\title{
CULTIVO DE FEIJOEIRO NO OUTONO/INVERNO ASSOCIADO À APLICAÇÃO DE BIOESTIMULANTE E ADUBO FOLIAR NA PRESENÇA E AUSENCIA DE IRRIGAÇÃO
}

\section{FALL/ WINTER BEAN CROP LOAM IN ASSOCIATION WITH BIOSTIMULANT APPLICATION AND FOLIAR FERTILIZER IN BOTH PRESENCE AND ABSENCE OF IRRIGATION}

\author{
Marizangela Rizzatti ÁVILA ${ }^{1}$ \\ Davi Antonio Oliveira BARIZÃO ${ }^{2}$ \\ Eder Pereira GOMES ${ }^{1}$ \\ Gregory FEDRI ${ }^{2}$ \\ Leandro Paiola ALBRECHT ${ }^{1}$
}

\section{RESUMO}

O objetivo do trabalho foi avaliar a eficiência da utilização de bioestimulante, cálcio (Ca) e boro (B) através de pulverização foliar em diferentes estádios fenológicos da cultura do feijoeiro cultivado em solo arenoso sob sistema irrigado e

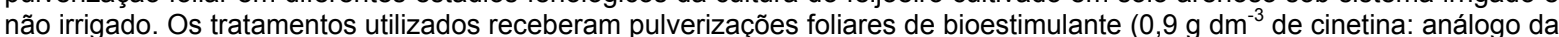
citocinina; $0,5 \mathrm{~g} \mathrm{dm}^{-3}$ de ácido giberélico: análogo da giberelina; e $0,5 \mathrm{~g} \mathrm{dm}^{-3}$ de ácido indol-butírico: análogo da auxina) na dose de $0,75 \mathrm{dm}^{3} \mathrm{ha}^{-1}$ e de $3 \mathrm{dm}^{3} \mathrm{ha}^{-1}$ de uma mistura de cálcio $(10 \%)$ e boro $(2 \%)$. As pulverizações foram efetuadas em dois estádios fenológicos da cultura, ou seja, V4 (emissão da terceira folha trifoliada) e R5 (aparecimento dos botões florais), de forma isolada ou combinada, em áreas com e sem irrigação, com exceção da testemunha (tratamento sem irrigação e pulverização). Analisando os resultados pode-se concluir que a irrigação, devido à freqüência de déficits hídricos que ocorreram na região Noroeste do Paraná, se confirma como uma ferramenta para promover o aumento de produtividade da cultura do feijoeiro. A aplicação de bioestimulante e Ca+B, associados ou não quando pulverizados em diferentes estádios fenológicos da cultura do feijoeiro não apresentou melhoria no desempenho da cultura.

Palavras-chave: produtividade; déficit hídrico; fito-hormônio; cálcio; boro.

\section{ABSTRACT}

The objective of this present study was to assess the efficacy on utilizing biostimulant and Calcium (Ca) and Boron (B) leaf sprays in different bean crop phenological stages in sandy soil, under irrigated and non-irrigated systems. Treatments utilized in this experiment received foliar biostimulant applications $\left(0.9 \mathrm{~g} \mathrm{dm}^{-3}\right.$ kinetin: kitocynin-related; $0.5 \mathrm{~g} \mathrm{dm}^{-3} \mathrm{giberelic}^{-1}$ acid: giberelin-related; and $0.5 \mathrm{~g} \mathrm{dm}^{-3}$ indolbutiric acid: auxin-related) in doses of $0.75 \mathrm{dm}^{3} \mathrm{ha}^{-1} \mathrm{e} \mathrm{de} 3 \mathrm{dm}^{3}$ ha ${ }^{-1}$ of a mixture of Calcium (10\%) and Boron (2\%). Applications were carried out during both V4 (third trifoliate leaf) and R5 (blooming) plant phenological stages, isolated or combined in areas with and without irrigation, except for the witness (treatment without irrigation and without spraying). Analyzing the results, it can be concluded that irrigation, because of the water deficit frequency that occurred in the northwest of Parana, is confirmed as a tool to promote productivity increased of the bean crop. The application of biostmulant and $\mathrm{Ca}+\mathrm{B}$, associated or not when sprayed at different phenological stages of the bean crop did not show improvement in culture performances.

Key words: yield; water deficit; phytohormone; calcium; boron.

\footnotetext{
${ }^{1}$ Professor (a) Adjunto da Universidade Estadual de Maringá, Departamento de Ciências Agronômicas - Campus Regional de Umuarama, Caixa Postal 65, Estrada da Paca s/n. Bairro São Cristóvão, CEP: 87507-190, Umuarama, Paraná, Brasil. E-mail: marizangela_rizzatti@hotmail.com (Autor para correspondência); ederpgomes@gmail.com; Ipalbrecht@yahoo.com.br.

${ }^{2}$ Acadêmico do curso de agronomia, Bolsista de Iniciação Científica (PIBIC). Departamento de Ciências Agronômicas - Campus Regional de Umuarama, Estrada da Paca s/n. Bairro São Cristóvão, 87507-190, Umuarama, Paraná, Brasil. E-mail: agrofedri@yahoo.com; deividy_17@hotmail.com
} 
ÁVILA, M.R. et al. Cultivo de feijoeiro no outono/inverno...

\section{INTRODUÇÃO}

O feijão é um alimento básico para o brasileiro o qual consome em média $16,2 \mathrm{~kg}_{\text {feijão }}{ }^{-1}$ $a^{-1}$ o que depende da região, classe econômica, cor do grão e preço (Hoffmann, 2000). No Brasil no ano agrícola 2006/2007 a produção de feijão média total foi de 1.568; 996,6; 775,2 mil toneladas, na primeira, segunda e terceira safra respectivamente, as quais são semeadas de agosto a dezembro; janeiro a março e de abril a julho, sendo a produtividade média 1.005; 585 e $941 \mathrm{~kg} \mathrm{ha}^{-1}$. Neste contexto o Estado do Paraná figura com uma produção de 558,1; 228,3 e 8,9 mil toneladas com produtividade de $1.390 ; 1.519$ e 722 kg ha ${ }^{-1}$ (CONAB, 2009), sendo a produção brasileira, particularmente do ano de 2006/2007 muito próxima a necessidade de demanda nacional deste alimento.

Contudo maiores produtividades podem ser alcançadas pela efetiva utilização de tecnologias já consolidadas para a cultura e com a introdução de novas tecnologias principalmente em regiões que possuem originalmente solos de textura arenosa e de baixa fertilidade e também melhorando as condições de cultivo da segunda e terceira safra principalmente pela utilização de irrigação, adubação foliar e bioestimulante.

No cultivo do feijoeiro a disponibilidade de água no solo para as plantas é fator preponderante para que estas possam alcançar elevada produção. O período mais crítico de ocorrência de déficit hídrico para as plantas do feijoeiro é o subperíodo entre o início do florescimento ao início do enchimento de grãos, porque nesta fase ocorre a maior demanda de água pela cultura, uma vez que coincide com a época de maior índice de área foliar e atividade fotossintética. Desta forma, déficit hídrico durante este período acarreta em redução de todos os componentes da produção e consequentemente em menores produtividades. Portanto a utilização de sistemas de irrigação onde a demanda hídrica da cultura não é suprida ao longo do seu ciclo e/ou em locais de cultivo onde os solos possuem baixa capacidade de retenção de água é essencial, tendo em vista as diferentes necessidades hídricas do feijoeiro em seus diferentes estádios de desenvolvimento visando um manejo adequado da irrigação, uma vez que trabalhos utilizando irrigação em feijoeiro indicam ganhos expressivos de produtividade (Rezende et al., 2002; Rezende et al., 2004; Jadoski et al., 2003).

Assim como a irrigação a associação dos nutrientes $\mathrm{Ca}+\mathrm{B}$ em pulverização foliar vem se mostrando promissora (Bevilaqua et al., 2002). As principais funções do cálcio e do boro são de atuar na formação do pectato de cálcio, na germinação do grão de pólen e crescimento do tubo polínico, contribuindo para a fecundação; translocação de açúcares e na formação da parede celular, metabolismo de carboidratos, funcionamento das membranas celulares e auxílio na boa produção e distribuição hormonal, é importante também para a formação das proteínas contribuindo para a maior massa e qualidade das sementes e consequentemente maior produtividade (Malavolta et al., 1997).

Bioestimulante é a mistura de dois ou mais reguladores vegetais e os reguladores vegetais são substâncias sintéticas que podem ser utilizadas isoladamente ou em misturas e quando aplicadas diretamente nas plantas e em baixas concentrações possuem ação similar aos grupos de hormônios vegetais (auxinas, giberelinas e citocininas) estas substâncias, inibem, promovem ou modificam processos morfológicos e fisiológicos com o intuito de elevar a produção e melhorar sua qualidade (Castro \& Vieira, 2001).

As auxinas promovem o crescimento das plantas, principalmente através do alongamento celular, seus efeitos fisiológicos dependem de alguns fatores como: estádio de desenvolvimento do tecido ou órgão; concentração; tipo, endógeno ou exógeno e, principalmente, a interação com outros reguladores vegetais (Taiz \& Zeiger, 2006). Segundo os mesmos autores, as giberelinas são associadas à promoção do crescimento do caule e a aplicação desse regulador vegetal à planta intacta pode induzir ao aumento significativo na sua altura e também relatam que as citocininas participam na regulação de muitos processos fisiológicos da planta, incluindo a divisão celular, a morfogênese da parte aérea e das raízes, a maturação dos cloroplastos, o alongamento celular e a senescência.

O momento correto para aplicação de bioestimulante ainda não está totalmente definido, em função de diversos fatores que podem influenciar neste processo, como as condições climáticas, que são diferentes de ano para ano, as condições culturais, classe de solo, controle de pragas, aspectos nutricionais, as relações águaplanta-atmosfera e as características e potencialidades genéticas das plantas (Vieira \& Monteiro, 2002) além da forma de aplicação que pode ser nas sementes através do tratamento antes da semeadura ou pulverização na linha de semeadura e via pulverização foliar que pode ser realizada em determinados estádios fenológicos dependendo da cultura que se utilizará o bioestimulante (Milléo et al., 2000; Ávila et al., 2008).

Estudos realizados com a interação de reguladores vegetais e adubação foliar de $\mathrm{Ca}+\mathrm{B}$ nas culturas do feijão e soja e em diferentes estágios fenológicos, cultivares e locais (Alleoni et al., 2000; Vieira \& Castro, 2004) tem revelado acréscimos em termos produtivos.

Os trabalhos realizados até o momento prestigiaram a utilização isolada de bioestimulante, $\mathrm{Ca}+\mathrm{B}$ ou irrigação, e não a sua associação, justificando mais estudos nesse sentido, uma vez que maiores produtividades podem ser alcançadas pela associação destes fatores utilizados de forma adequada. Assim, o objetivo desse trabalho foi avaliar a eficiência da utilização de pulverização foliar de bioestimulante associado ou não à 
ÁVILA, M.R. et al. Cultivo de feijoeiro no outono/inverno...

adubação foliar com $\mathrm{Ca}+\mathrm{B}$ em diferentes estádios fenológicos da cultura do feijoeiro cultivado no outono/inverno em solo arenoso sob sistema irrigado e não irrigado.

\section{MATERIAL E MÉTODOS}

O experimento foi conduzido em área localizada na Fazenda do Campus Regional de Umuarama em Umuarama - PR, pertencente à Universidade Estadual de Maringá. O clima predominante na região é do tipo Cfa (mesotérmico úmido, com chuvas abundantes no verão e inverno seco com verões quentes), segundo classificação de Köppen.

Umuarama está situada a uma latitude de $23^{\circ} 47^{\prime}$ sul e longitude de 53 $14^{\prime}$ a oeste de Greenwhich, com altitude de $403 \mathrm{~m}$, e solo classificado como Latossolo Vermelho Distrófico típico com horizonte A apresentando textura arenosa e horizonte diagnóstico subsuperficial $B$ latossólico apresentando textura franco-arenosa (EMBRAPA, 1999).

A semeadura foi realizada na segunda quinzena do mês de março de 2008, sob palhada de Brachiaria spp., utilizando sementes de feijão da cultivar IPR Colibri "carioca", grupo de maturação precoce e tipo I. O espaçamento de semeadura utilizado foi de $0,50 \mathrm{~m}$, na profundidade aproximada de $0,05 \mathrm{~m}$, com de 12 sementes viáveis por metro linear, perfazendo uma população de 240.000 plantas $\mathrm{ha}^{-1}$.

A adubação e correção do solo foram realizadas de acordo com recomendações de Vieira
(2008) com base nas características químicas do solo que apresentou os seguintes valores: $\mathrm{pH}$ $\left(\mathrm{CaCl}_{2}\right)$ de 4,4; M.O. de $1,3 \mathrm{~g} \mathrm{dm}^{-3} ; \mathrm{P}$ de $11 \mathrm{mg}$ $\mathrm{dm}^{-3} ; \mathrm{B}$ de $0,2 \mathrm{~g} \mathrm{dm}^{-3} ; 0,08 ; 1,05 ; 0,58 ; 4,61$ e 0,6 $\mathrm{mmol}_{\mathrm{c}} \mathrm{dm}^{-3}$, de K; Ca; $\mathrm{Mg} ; \mathrm{H}+\mathrm{Al}$ e $\mathrm{Al}$, respectivamente. Foram aplicados inseticidas, à base de Metamidofós e Thiamethoxan para o controle de Bemisia tabaci, Liriomyza sp., Elasmopalpus lignosellus e Diabrotica speciosa, e herbicida seletivo para a cultura do feijoeiro, à base de Fomesafen.

O delineamento experimental utilizado foi em blocos casualizados com quatro repetições em esquema de parcela sub-dividida, onde as parcelas foram compostas pelos tratamentos irrigado e não irrigado, e as sub-parcelas pelos tratamentos com bioestimulante e $\mathrm{Ca}+\mathrm{B}$.

As parcelas foram constituídas por seis linhas de $35 \mathrm{~m}$ de comprimento cada, e divididas em sete sub-parcelas de $5 \mathrm{~m}$ de comprimento, sendo a área total de cada parcela e sub-parcela de 105 e $15 \mathrm{~m}^{2}$ respectivamente. Após a semeadura a área foi irrigada a fim de que, no início do ciclo, as condições de umidade do solo fossem idênticas.

Os tratamentos utilizados receberam pulverizações foliares de bioestimulante, $\mathrm{Ca}+\mathrm{B}$ em dois estádios fenológicos da cultura, ou seja, V4 (emissão da terceira folha trifoliada) e R5 (aparecimento dos botões florais), de forma isolada ou combinada, em áreas com e sem irrigação, com exceção das testemunhas. O esquema detalhado dos tratamentos encontra-se apresentado na Tabela 1.

TABELA 1 - Esquema dos tratamentos utilizados no experimento

\begin{tabular}{|c|c|c|c|}
\hline N. & Irrigação & Produtos & Estádio Fenológico ${ }^{1}$ \\
\hline 1 & Não & - & - \\
\hline 2 & Sim & - & - \\
\hline 3 & Não & Bioestimulante & V4 \\
\hline 4 & Sim & Bioestimulante & V4 \\
\hline 5 & Não & Bioestimulante & R5 \\
\hline 6 & Sim & Bioestimulante & R5 \\
\hline 7 & Não & Bioestimulante $+(\mathrm{Ca}+\mathrm{B})$ & R5 \\
\hline 8 & Sim & Bioestimulante $+(\mathrm{Ca}+\mathrm{B})$ & R5 \\
\hline 9 & Não & Bioestimulante $+(\mathrm{Ca}+\mathrm{B})$ & $\mathrm{V} 4+\mathrm{R} 5$ \\
\hline 10 & Sim & Bioestimulante $+(\mathrm{Ca}+\mathrm{B})$ & $\mathrm{V} 4+\mathrm{R} 5$ \\
\hline 11 & Não & $($ Bioestimulante + Bioestimulante $)+(\mathrm{Ca}+\mathrm{B})$ & $(\mathrm{V} 4+\mathrm{R} 5)+\mathrm{R} 5$ \\
\hline 12 & Sim & (Bioestimulante + Bioestimulante $)+(\mathrm{Ca}+\mathrm{B})$ & $(\mathrm{V} 4+\mathrm{R} 5)+\mathrm{R} 5$ \\
\hline 13 & Não & $(\mathrm{Ca}+\mathrm{B})$ & R5 \\
\hline 14 & Sim & $(\mathrm{Ca}+\mathrm{B})$ & R5 \\
\hline
\end{tabular}

${ }^{1}$ V4 (emissão da terceira folha trifoliada) e R5 (aparecimento dos botões florais). 
ÁVILA, M.R. et al. Cultivo de feijoeiro no outono/inverno...

O manejo da irrigação para os tratamentos irrigados iniciou-se após a semeadura, estes foram manejados a partir de leituras obtidas de um tanque Classe A. A evaporação do tanque foi relacionada com a velocidade do vento e com a umidade relativa do ar, obtendo-se, a ETo (evapotranspiração de referência). Por fim, o produto de ETo por Kc (coeficientes de cultura) forneceu a evapotranspiração de cultura (ETc). Os valores de Kc foram adotados conforme Doorenbos \& Kassan (1994) sendo estes valores divididos por estádios fenológicos: Kc de estabelecimento, 0,3; desenvolvimento, 0,7; florescimento, 1 ; frutificação, 0,7 e maturação, 0,3 .

$\mathrm{O}$ aspersor utilizado foi o Fabrimar $^{\circledR}$ modelo Eco A232 com capacete verde, que submetido a uma pressão de serviço de 2,94 kPa apresenta uma vazão de $1,31 \mathrm{~m}^{3} \mathrm{~h}^{-1}$ com um diâmetro da área de aplicação de $26 \mathrm{~m}$.

A irrigação foi realizada em esquema de turno de rega fixo, sendo efetuada 3 vezes por semana e a lâmina de irrigação aplicada foi estimada de acordo com a ETc ocorrida entre os dias de irrigação.
O balanço hídrico e as temperaturas máxima, média e mínima para o período de condução do experimento encontram-se na Figura $1 \mathrm{~A}$ e C. A comparação do tratamento irrigado e não irrigado encontra-se na Figura $1 \mathrm{~B}$. $\mathrm{O}$ balanço hídrico foi realizado a partir dos dados de evapotranspiração de cultura e precipitação, fornecidos pela Estação Agroclimática da Universidade Estadual de Maringá, Campus Regional de Umuarama. Esses dados foram lançados no programa BHNORM versão 5 (Rolim \& Sentelhas, 1999) para elaboração do gráfico de balanço hídrico através da metodologia proposta por Thornthwaite \& Mather (1955) e A capacidade de água disponível no solo (CAD) foi estimada segundo Gomes \& Testezlaf (2008) que recomendam para solos de textura arenosa um valor de $100 \mathrm{~mm} \mathrm{~m}^{-1}$, no entanto, considerando a profundidade efetiva do sistema radicular da cultura do feijoeiro igual a 0,4 m, passa-se a ter um CAD de $40 \mathrm{~mm}$. Esse valor de CAD foi também utilizado para alimentar o programa BHNORM versão 5.

(A)

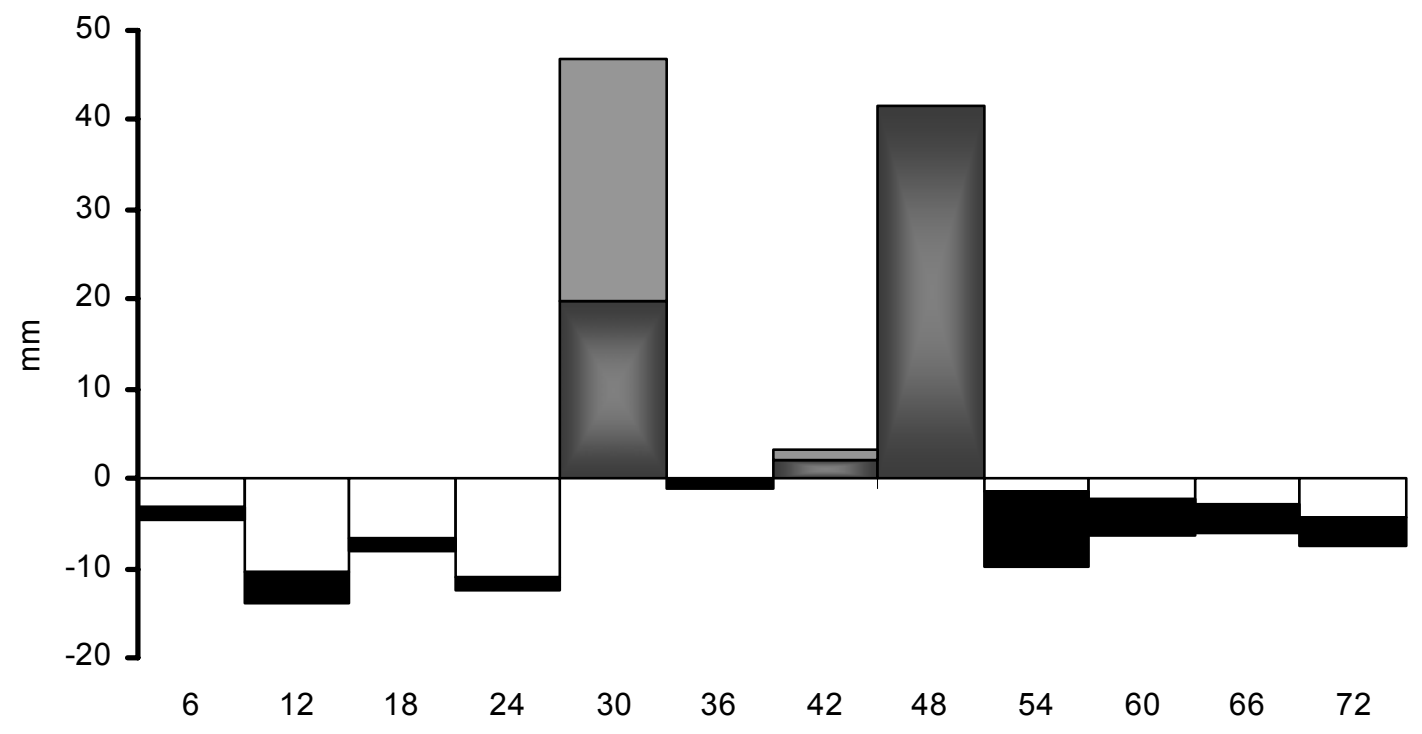

$\square$ Deficiência $\square$ Excedente $\square$ Retirada $\square$ Reposição

FIGURA 1 - Balanço hídrico (A), chuva e balanço hídrico simplificado dos tratamentos irrigado e não irrigado (B) e temperaturas máxima, média e mínima $(\mathrm{C})$ de Umuarama, Estado do Paraná, durante o período de condução do experimento. Fonte: Estação Agroclimática da Universidade Estadual de Maringá, Campus Regional de Umuarama, 2008. 
(B)

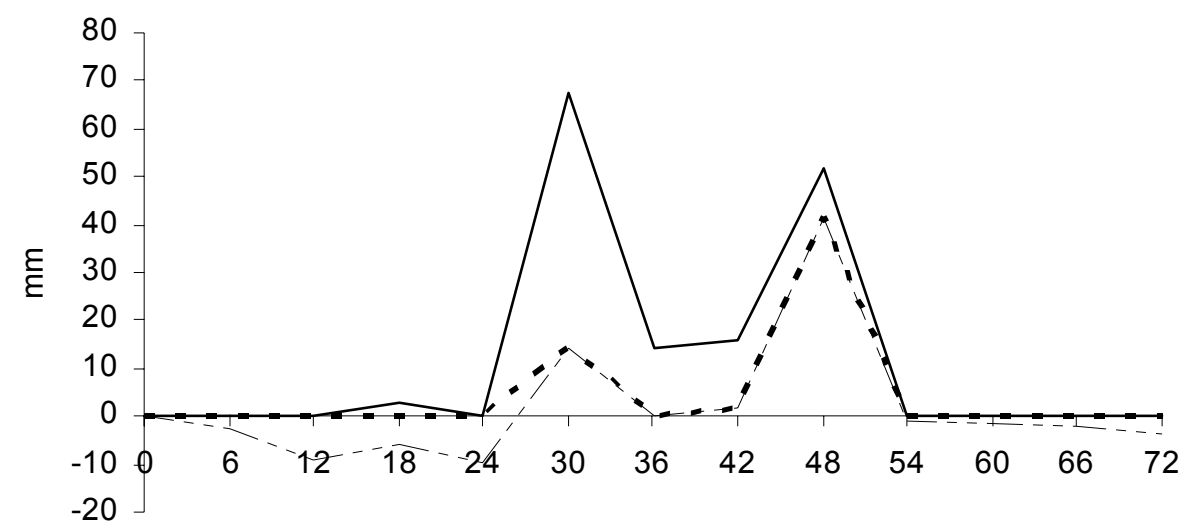

Ciclo (dias)

(C)

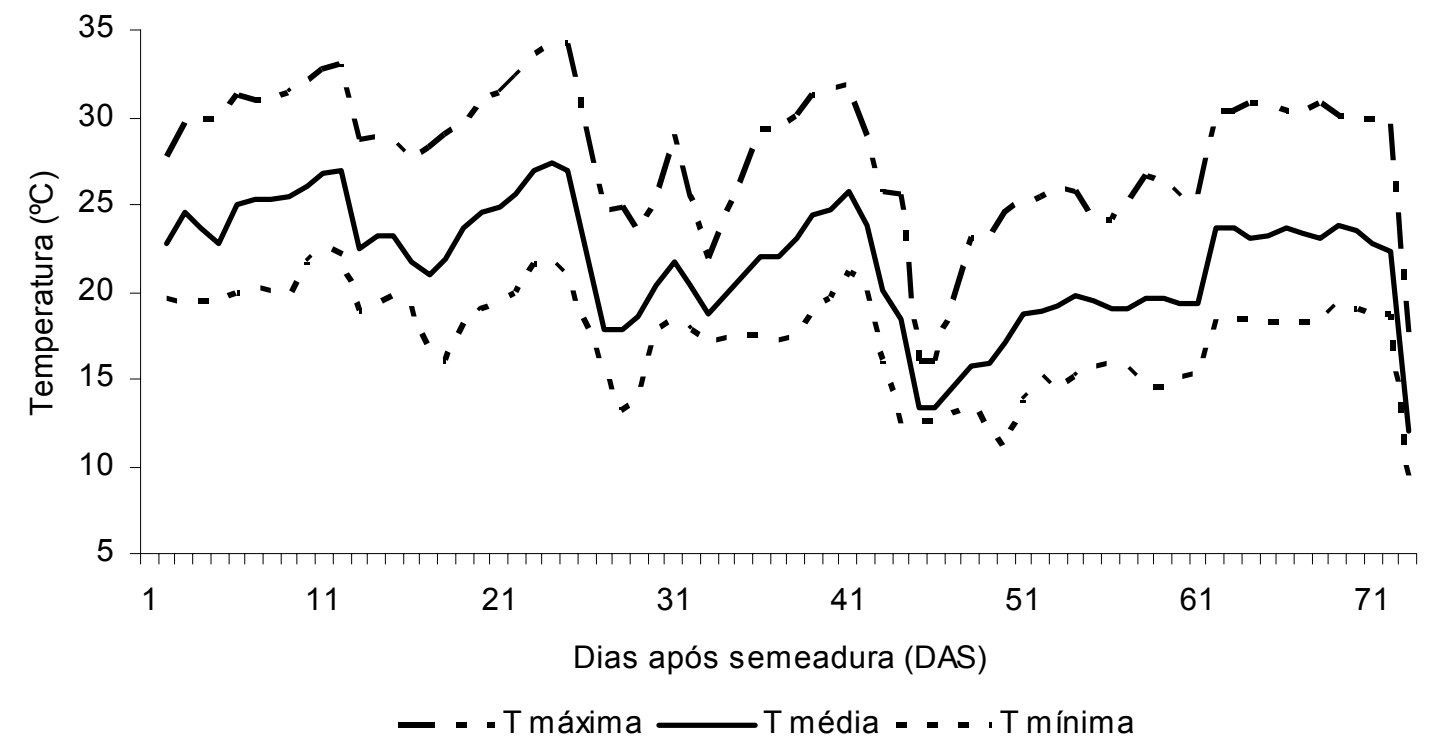

FIGURA 1 - (CONTINUAÇÃO) Balanço hídrico (A), chuva e balanço hídrico simplificado dos tratamentos irrigado e não irrigado $(B)$ e temperaturas máxima, média e mínima $(C)$ de Umuarama, Estado do Paraná, durante o período de condução do experimento. Fonte: Estação Agroclimática da Universidade Estadual de Maringá, Campus Regional de Umuarama, 2008. 
ÁVILA, M.R. et al. Cultivo de feijoeiro no outono/inverno...

O bioestimulante utilizado foi o Stimulate ${ }^{\circledR}$, composto por três reguladores vegetais: $0,09 \mathrm{~g} \mathrm{dm}^{-3}$ de cinetina (análogo de citocinina), $0,05 \mathrm{~g} \mathrm{dm}^{-3} \mathrm{de}$ ácido giberélico (análogo de giberelina) e $0,05 \mathrm{~g}$ $\mathrm{dm}^{-3}$ de ácido indol-butírico (análogo de auxina) pulverizado em diferentes doses de acordo com a Tabela 1

$O$ produto utilizado para fornecer $\mathrm{Ca}+\mathrm{B}$ é caracterizado como SETT ${ }^{\circledR}$, um fertilizante líquido composto de $10 \%$ de Cálcio e $2 \%$ de Boro com densidade de 1,45 , que foi aplicado na dose de 3 $\mathrm{dm}^{3} \mathrm{ha}^{-1}$.

As pulverizações foliares foram efetuadas com o auxílio de um pulverizador costal propelido a $\mathrm{CO}_{2}$, com pressão constante de $280 \mathrm{kPa}$, equipado com lança contendo 1 bico leque da série Teejet tipo XR 110:02, que, trabalhando a uma altura de $0,40 \mathrm{~m}$ do alvo e a uma velocidade de $1 \mathrm{~m} \mathrm{~s}^{-1}$, atingiu uma faixa aplicada de $0,46 \mathrm{~m}$ de largura e propiciou um volume de calda de $200 \mathrm{dm}^{3} \mathrm{ha}^{-1}$.

A água utilizada para o preparo das soluções foi destilada e estavam com $\mathrm{pH}$ 7. Contudo o $\mathrm{pH}$ da calda foi ajustado para 4,5 com o produto P51, em todas as soluções adicionou-se $0,5 \%$ de Natur'L Óleo ${ }^{\circledR}$, pois este atua como produto espalhante adesivo, reduzindo assim as perdas das soluções em questão por deriva ou lavagem em decorrência da irrigação.

A pulverização em $\mathrm{V} 4$ foi realizada dia $05 / 04 / 2008$, às $16 \mathrm{~h}$, com temperatura média de 25 ${ }^{\circ} \mathrm{C}$, umidade relativa de $65 \%$ e velocidade do vento de $1 \mathrm{~km} \mathrm{~h}^{-1}$; R5 no dia 24/04/2008, às $9 \mathrm{~h}$, com temperatura média de $22{ }^{\circ} \mathrm{C}$, umidade relativa de $70 \%$ e velocidade do vento de $0,6 \mathrm{~km} \mathrm{~h}^{-1}$.

Para as avaliações, foram consideradas apenas as quatro fileiras centrais, descartando-se $0,5 \mathrm{~m}$ de cada extremidade, totalizando, assim, uma área útil de $8 \mathrm{~m}^{2}$ por sub-parcela.

Antes da colheita, avaliou-se mediante a escolha aleatória de 15 plantas na área útil de cada parcela a altura das plantas e a altura de inserção da primeira vagem com 0 auxílio de régua milimetrada expressando os resultados em centímetros. O número de vagens por planta, foi obtido através da contagem de vagens presentes em cada planta e o número de sementes por vagem, contando-se o número de sementes de cada vagem das 15 plantas escolhidas na amostragem.

Após as avaliações de campo as plantas foram colhidas manualmente, oito dias após o ponto de maturação fisiológica. Posteriormente a colheita das plantas, as sementes foram debulhadas das vagens em máquina trilhadoura estacionária, limpas com o auxílio de peneiras, secas em condições naturais e acondicionadas em sacos de papel kraft.

Partindo-se do rendimento de grãos nas parcelas, foram calculadas as produtividades em $\mathrm{kg}$ ha $^{-1}$. O grau de umidade das sementes foi determinado por meio do método de estufa a $105 \pm 1$ ${ }^{\circ} \mathrm{C}$ por $24 \mathrm{~h}$ (BRASIL, 1992) e corrigido para $130 \mathrm{~g}$ $\mathrm{kg}^{-1}$. Em seguida, determinou-se a massa de mil sementes (g), por meio da pesagem de oito subamostras de 100 sementes, para cada repetição de campo, com o auxílio de balança analítica com precisão de 0,001 g, multiplicando-se os resultados por 10 (BRASIL, 1992).

A análise estatística consistiu da análise de variância dos dados para verificar a presença de diferença significativa $(P<0,05)$ entre os tratamentos isolados e de sua interação. Verificada a existência de diferença estatística pelo teste $F$, enquanto as médias dos tratamentos com bioestimulante, adubação foliar com $\mathrm{Ca}+\mathrm{B}$ em diferentes estádios fenológicos da cultura do feijoeiro foram comparadas pelo teste de Tukey a $5 \%$ de probabilidade. Para comparação dos tratamentos irrigados e não irrigado utilizou-se a análise de variância conclusiva pelo teste $\mathrm{F}$ a $5 \%$ de probabilidade (Banzato \& Kronka, 2006).

\section{RESULTADOS E DISCUSSÃO}

O resultado da análise de variância apresentou interação significativa dos tratamentos com bioestimulante e adubação foliar com $\mathrm{Ca}+\mathrm{B}$ nas diferentes fases de desenvolvimento da cultura do feijoeiro $x$ presença ou ausência de irrigação para todos os componentes de produção do feijoeiro, bem como para altura de planta $e$ produtividade.

Na Figura $1 \mathrm{~A}$, pode-se perceber a existência de deficiência hídrica nos primeiros 24 dias após semeadura, período entre a emergência e parte da pré-floração da cultura. A deficiência hídrica acumulada neste período foi de $27,3 \mathrm{~mm}$ e a retirada de água do solo pela cultura igual $11,9 \mathrm{~mm}$, insuficiente para repor a demanda hídrica necessária à cultura. No período compreendido entre 24 e 30 dias após semeadura ocorreram chuvas da ordem de $67,4 \mathrm{~mm}$, suficiente para elevar o solo à capacidade de campo e ainda obter um excedente hídrico de $14 \mathrm{~mm}$. Dos 30 aos 36 dias ocorre uma retirada de água do solo da ordem $1,2 \mathrm{~mm}$, insuficiente para causar déficit hídrico à cultura. No período compreendido entre 36 e 54 dias (início da frutificação), têm-se um período hídrico excedente da ordem de 43,7 mm. Enquanto que entre 54 e 66 dias ocorre uma deficiência hídrica acumulada igual a $5,1 \mathrm{~mm}$, afetando o final da frutificação. A partir de 66 dias após semeadura em diante, a deficiência de água no solo igual a 3,6 $\mathrm{mm}$ não se faz problema, mas é desejável ao início da maturação. Portanto, pode-se perceber que ocorrem dois momentos críticos de deficiência de água no solo durante o cultivo do feijoeiro, o primeiro até os 24 dias e, o segundo, entre 54 e 66 dias após a semeadura. No segundo período, a deficiência hídrica foi menor devido à utilização de maiores valores de coeficientes de cultura associados aos menores valores de temperaturas médias (Figura 1C) e conseqüentemente menores valores de evapotranspiração. Para se comparar a chuva e balanço hídrico simplificado dos tratamentos irrigado e não irrigado, pode-se utilizar a Figura $1 \mathrm{~B}$, onde observa-se que nos primeiros 24 dias de cultivo a irrigação manteve o solo na capacidade de campo, o mesmo ocorrendo a partir 
ÁVILA, M.R. et al. Cultivo de feijoeiro no outono/inverno...

de 54 dias após a semeadura.

Através dos resultados apresentados na Tabela 2, verifica-se que para altura de plantas não houve diferença significativa $(P<0,05)$ entre os tratamentos das sub-parcelas. Porém pode-se notar que houve diferença na altura de plantas quando se comparou os tratamentos de cada parcela, onde as parcelas irrigadas apresentaram plantas com maior estatura em todos os níveis de tratamento em comparação às parcelas não irrigadas. Ainda em relação à Tabela 2 pode-se notar que não houve diferença significativa $(P<0,05)$ em nenhum dos fatores de tratamento quando se analisa altura de inserção da primeira vagem, ou seja, a altura de inserção de primeira vagem não foi influenciada positivamente pela utilização de bioestimulante, adubação foliar e irrigação uma vez que obtivemos diferenças na altura de plantas, porém esta diferença não foi significativa estatisticamente, mas se observarmos em termos de valores a inserção da primeira vagem foi em média $1 \mathrm{~cm}$ maior nos tratamentos que receberam irrigação.

TABELA 2 - Altura das plantas $(\mathrm{cm})$ e a altura de inserção da primeira vagem $(\mathrm{cm})$ de plantas de feijoeiro submetidas a pulverizações de Bioestimulante e Cálcio + Boro. Umuarama, PR, 2008.

\begin{tabular}{|c|c|c|c|c|c|c|}
\hline \multirow{3}{*}{ Produto } & \multirow{3}{*}{ Dose $\left(\mathrm{dm}^{3} \mathrm{ha}^{-1}\right)$} & \multirow{3}{*}{$\begin{array}{l}\text { Estádio } \\
\text { fenológico }\end{array}$} & \multicolumn{4}{|c|}{ Irrigação $^{2}$} \\
\hline & & & \multicolumn{2}{|c|}{ Altura de Planta } & \multicolumn{2}{|c|}{$\begin{array}{c}\text { Altura de inserção } \\
\text { primeira vagem }\end{array}$} \\
\hline & & & Ausência & Presença & Ausência & Presença \\
\hline Testemunha & - & - & $24,75 \mathrm{~A} \mathrm{~b}$ & $30,45 \mathrm{~A} \mathrm{a}$ & $8,42 \mathrm{~A} a$ & $9,07 \mathrm{~A} a$ \\
\hline BIOESTIMULANTE (BIO) & 0,75 & V4 & $25,45 \mathrm{~A} \mathrm{~b}$ & $31,85 \mathrm{~A} \mathrm{a}$ & $8,90 \mathrm{~A}$ a & $9,30 \mathrm{Aa}$ \\
\hline $\mathrm{BIO}$ & 0,75 & R5 & $26,70 \mathrm{~A} \mathrm{~b}$ & $29,25 \mathrm{~A} \mathrm{a}$ & $8,70 \mathrm{~A}$ a & $8,75 \mathrm{Aa}$ \\
\hline $\mathrm{BIO}+(\mathrm{Ca}+\mathrm{B})$ & $0,75+3,0$ & R5 & $26,05 \mathrm{~A} \mathrm{~b}$ & $29,15 \mathrm{~A}$ a & $7,80 \mathrm{~A}$ a & $9,25 \mathrm{Aa}$ \\
\hline $\mathrm{BIO}+(\mathrm{Ca}+\mathrm{B})$ & $0,75+3,0$ & V4+R5 & $24,75 \mathrm{~A} \mathrm{~b}$ & $28,80 \mathrm{~A} \mathrm{a}$ & $7,70 \mathrm{~A}$ a & $9,85 \mathrm{~A}$ a \\
\hline$(\mathrm{BIO}+\mathrm{BIO})+(\mathrm{Ca}+\mathrm{B})$ & $(0,35+0,35)+3,0$ & $(\mathrm{~V} 4+\mathrm{R} 5)+\mathrm{R} 5$ & $23,75 \mathrm{~A} \mathrm{~b}$ & $30,70 \mathrm{~A} \mathrm{a}$ & $8,20 \mathrm{~A} a$ & $9,10 \mathrm{~A}$ a \\
\hline$(\mathrm{Ca}+\mathrm{B})$ & 3,0 & R5 & $25,05 \mathrm{~A} \mathrm{~b}$ & $32,45 \mathrm{~A} \mathrm{a}$ & $8,20 \mathrm{~A} a$ & $9,55 \mathrm{~A}$ a \\
\hline Média & & & 25,21 & 30,37 & 8,42 & 9,07 \\
\hline C.V. (Parcela) \% & & & \multicolumn{2}{|c|}{5,79} & \multicolumn{2}{|c|}{12,09} \\
\hline C.V. (Sub-parcela) \% & & & \multicolumn{2}{|c|}{8,74} & \multicolumn{2}{|c|}{10,25} \\
\hline D.M.S. ${ }^{3}$ & & & \multicolumn{2}{|c|}{4,79} & \multicolumn{2}{|c|}{1,40} \\
\hline
\end{tabular}

O número de vagens por planta (Tabela 3 ) aumentou independentemente de se utilizar bioestimulante e adubação foliar com $\mathrm{Ca}+\mathrm{B}$ nas diferentes fases de desenvolvimento da cultura, se observando maior número de vagens quando se utilizou irrigação. Quando se compara a pulverização de bioestimulante e adubação foliar com $\mathrm{Ca}+\mathrm{B}$ nas diferentes fases de desenvolvimento nos tratamentos que não receberam irrigação verifica-se que a aplicação com bioestimulante não proporcionou maior número de vagens por planta em comparação à aplicação de $\mathrm{Ca}+\mathrm{B}$ isolada. A única diferença observada foi do tratamento com bioestimulante sobre a testemunha, ou seja, 13 vagens por planta. Para aqueles tratamentos que receberam irrigação verifica-se que o maior número de vagens foi alcançado quando se realizou a pulverização das plantas com $\mathrm{BIO}+(\mathrm{Ca}+\mathrm{B})$ em $\mathrm{V} 4+\mathrm{R} 5$ e o menor número de vagens foi encontrado quando não se realizou tratamento das plantas (Testemunha), ou quando, somente receberam pulverização com $\mathrm{Ca}+\mathrm{B}$ no início do aparecimento dos botões florais, apresentando 21 vagens por planta em ambos tratamentos, desta forma, para se ter maior número de vagens por planta quando o cultivo é irrigado pode-se pulverizar $\mathrm{BIO}+(\mathrm{Ca}+\mathrm{B})$ em $\mathrm{V} 4+\mathrm{R} 5$ para que a planta consiga apresentar maior numero de vagens. 
ÁVILA, M.R. et al. Cultivo de feijoeiro no outono/inverno...

TABELA 3 - Número de vagens por planta e número de sementes por vagem de plantas de feijoeiro submetidas a pulverizações de Bioestimulante e Cálcio + Boro. Umuarama, PR, 2008.

\begin{tabular}{|c|c|c|c|c|c|c|}
\hline \multicolumn{3}{|c|}{ Pulverizações $^{1}$} & \multicolumn{4}{|c|}{ Irrigação $^{2}$} \\
\hline \multirow[t]{2}{*}{ Produto } & \multirow[t]{2}{*}{ Dose $\left(\mathrm{dm}^{3} \mathrm{ha}^{-1}\right)$} & \multirow{2}{*}{$\begin{array}{l}\text { Estádio } \\
\text { fenológico }\end{array}$} & \multicolumn{2}{|c|}{$\begin{array}{l}\text { Número de vagens } \\
\text { por planta }\end{array}$} & \multicolumn{2}{|c|}{$\begin{array}{c}\text { Número de sementes } \\
\text { por vagem }\end{array}$} \\
\hline & & & Ausência & Presença & Ausência & Presença \\
\hline $\begin{array}{l}\text { Testemunha } \\
\text { BIOESTIMULANTE (BIO) }\end{array}$ & $\begin{array}{c}- \\
0,75\end{array}$ & $\begin{array}{l}- \\
\text { V4 }\end{array}$ & $\begin{array}{c}13 \mathrm{~B} \mathrm{~b} \\
15 \mathrm{AB} \mathrm{b}\end{array}$ & $\begin{array}{c}21 \mathrm{~B} \mathrm{a} \\
28 \mathrm{AB} \mathrm{a}\end{array}$ & $\begin{array}{l}6 \mathrm{Aa} \\
6 \mathrm{~A} \mathrm{a}\end{array}$ & $\begin{array}{l}6 \mathrm{Aa} \\
6 \mathrm{~A} \mathrm{a}\end{array}$ \\
\hline $\begin{array}{l}\mathrm{BIO} \\
\mathrm{BIO}+(\mathrm{Ca}+\mathrm{B}) \\
\mathrm{BIO}+(\mathrm{Ca}+\mathrm{B}) \\
(\mathrm{BIO}+\mathrm{BIO})+(\mathrm{Ca}+\mathrm{B}) \\
(\mathrm{Ca}+\mathrm{B})\end{array}$ & $\begin{array}{c}0,75 \\
0,75+3,0 \\
0,75+3,0 \\
(0,35+0,35)+3,0 \\
3,0\end{array}$ & $\begin{array}{c}\mathrm{R} 5 \\
\mathrm{R} 5 \\
\mathrm{~V} 4+\mathrm{R} 5 \\
(\mathrm{~V} 4+\mathrm{R} 5)+\mathrm{R} 5 \\
\mathrm{R} 5\end{array}$ & $\begin{array}{l}22 \mathrm{~A} a \\
19 \mathrm{AB} b \\
16 \mathrm{AB} b \\
16 \mathrm{AB} b \\
18 \mathrm{AB} \mathrm{b}\end{array}$ & $\begin{array}{l}22 \mathrm{AB} \text { a } \\
25 \mathrm{AB} \text { a } \\
29 \mathrm{~A} \mathrm{a} \\
23 \mathrm{AB} \mathrm{a} \\
21 \mathrm{~B} \mathrm{a}\end{array}$ & $\begin{array}{l}6 \mathrm{Aa} \\
5 \mathrm{AB} \mathrm{a} \\
6 \mathrm{Aa} \\
4 \mathrm{~B} \mathrm{a} \\
6 \mathrm{~A} \mathrm{a}\end{array}$ & $\begin{array}{l}6 \mathrm{~A} \mathrm{a} \\
6 \mathrm{Aa} \\
6 \mathrm{Aa} \\
6 \mathrm{~A} \mathrm{a} \\
6 \mathrm{~A} \mathrm{a}\end{array}$ \\
\hline Média & & & 17 & 24 & 5 & 6 \\
\hline C.V. (Parcela) \% & & & \multicolumn{2}{|c|}{6,06} & \multicolumn{2}{|c|}{4,45} \\
\hline C.V. (Sub-parcela) \% & & & \multicolumn{2}{|c|}{17,71} & \multirow{2}{*}{\multicolumn{2}{|c|}{11,04}} \\
\hline D.M.S. ${ }^{3}$ & & & \multicolumn{2}{|c|}{5,69} & 1,35 & \\
\hline
\end{tabular}

${ }^{1}$ Médias seguidas de mesma letra maiúscula, em cada coluna, não diferem entre si de acordo com o teste de Tukey, a 5\% de probabilidade.

${ }^{2}$ Médias seguidas de mesma letra minúscula, em cada linha, não diferem entre si pelo teste $F$, a $5 \%$ de probabilidade.

${ }^{3}$ D.M.S. (Diferença Mínima Significativa) para o teste de Tukey, a $5 \%$ de probabilidade.

${ }^{4}$ V4 (emissão da terceira folha trifoliada) e R5 (aparecimento dos botões florais).

Para o número de sementes por vagem (Tabela 3) quando se compara as pulverizações de bioestimulante e adubação foliar com Ca+B nas diferentes fases de desenvolvimento da cultura nos tratamentos que a pulverização com $(\mathrm{BIO}+\mathrm{BIO})+$ (Ca+B) aplicada em V4+R5 foi menor em relação aos demais tratamentos com exceção aos demais tratamentos que receberam $\mathrm{BIO}+(\mathrm{Ca}+\mathrm{B})$, enquanto que para aqueles tratamentos que receberam irrigação observou-se que não houve diferenças significativas $(P<0,05)$ entre as pulverizações.

Os resultados da massa de mil sementes e produtividade da cultura do feijoeiro submetida a diferentes tratamentos estão apresentados na Tabela 4, estes confirmam maior massa de mil sementes e maior produtividade quando a cultura do feijoeiro foi irrigada independentemente de se utilizar ou não bioestimulante ou adubação foliar com Ca+B. Quando se compara a massa de mil sementes e produtividade do tratamento que não recebeu irrigação e receberam pulverizações com bioestimulante e/ou $\mathrm{Ca}+\mathrm{B}$ nos diferentes estádios fenológicos, observa-se que não houve diferença significativa $(P<0,05)$ ocorrendo o mesmo com o tratamento que recebeu irrigação.

TABELA 4 - Massa de mil sementes (g) e produtividade $\left(\mathrm{kg} \mathrm{ha}^{-1}\right)$ da cultura do feijoeiro submetida a pulverizações de Bioestimulante e Cálcio + Boro. Umuarama, PR, 2008.

\begin{tabular}{|c|c|c|c|c|c|c|}
\hline \multirow{3}{*}{ Produto } & \multicolumn{2}{|c|}{ ulverizações $^{1}$} & \multicolumn{4}{|c|}{ Irrigação $^{2}$} \\
\hline & \multirow{2}{*}{ Dose $\left(\mathrm{dm}^{-3} \mathrm{ha}^{-1}\right)$} & \multirow{2}{*}{$\begin{array}{l}\text { Estádio } \\
\text { fenológico }\end{array}$} & \multicolumn{2}{|c|}{$\begin{array}{l}\text { Massa de mil } \\
\text { sementes }\end{array}$} & \multicolumn{2}{|c|}{ Produtividade } \\
\hline & & & Ausência & Presença & Ausência & Presença \\
\hline Testemunha & - & - & $207 \mathrm{~A} \mathrm{~b}$ & $222 \mathrm{~A} a$ & $623 \mathrm{~A} \mathrm{~b}$ & $767 \mathrm{~A} a$ \\
\hline BIOESTIMULANTE (BIO) & 0,75 & V4 & 194 A b & $217 \mathrm{~A} a$ & $657 \mathrm{~A} \mathrm{~b}$ & $871 \mathrm{~A} a$ \\
\hline $\mathrm{BIO}$ & 0,75 & R5 & $208 \mathrm{~A} a$ & $207 \mathrm{~A}$ a & $647 \mathrm{~A} \mathrm{~b}$ & $775 \mathrm{~A}$ a \\
\hline $\mathrm{BIO}+(\mathrm{Ca}+\mathrm{B})$ & $0,75+3,0$ & R5 & $205 \mathrm{~A} \mathrm{~b}$ & $220 \mathrm{~A} a$ & $567 \mathrm{~A} \mathrm{~b}$ & $869 \mathrm{~A} a$ \\
\hline $\mathrm{BIO}+(\mathrm{Ca}+\mathrm{B})$ & $0,75+3,0$ & V4+R5 & $204 \mathrm{~A}$ a & $201 \mathrm{~A} a$ & $522 \mathrm{~A} b$ & $682 \mathrm{~A}$ a \\
\hline$(\mathrm{BIO}+\mathrm{BIO})+(\mathrm{Ca}+\mathrm{B})$ & $(0,35+0,35)+3,0$ & $(\mathrm{~V} 4+\mathrm{R} 5)+\mathrm{R} 5$ & $206 \mathrm{~A} \mathrm{~b}$ & $213 \mathrm{~A} a$ & $583 \mathrm{~A} \mathrm{~b}$ & $680 \mathrm{~A} \mathrm{a}$ \\
\hline$(\mathrm{Ca}+\mathrm{B})$ & 3,0 & R5 & $200 \mathrm{~A} \mathrm{~b}$ & $215 \mathrm{~A} \mathrm{a}$ & $590 \mathrm{~A} \mathrm{~b}$ & $783 \mathrm{~A} \mathrm{a}$ \\
\hline Média & & & 205 & 215 & 527 & 767 \\
\hline C.V. (Parcela) & & & \multicolumn{2}{|c|}{4,42} & \multicolumn{2}{|c|}{3,58} \\
\hline C.V. (Sub-parcela) & & & \multicolumn{2}{|c|}{11,04} & \multicolumn{2}{|c|}{21,87} \\
\hline D.M.S. ${ }^{3}$ & & & \multicolumn{2}{|c|}{28,89} & \multicolumn{2}{|c|}{222,67} \\
\hline
\end{tabular}

${ }^{1}$ Médias seguidas de mesma letra maiúscula, em cada coluna, não diferem entre si de acordo com o teste de Tukey, a $5 \%$ de probabilidade.

${ }^{2}$ Médias seguidas de mesma letra minúscula, em cada linha, não diferem entre si pelo teste $\mathrm{F}$, a $5 \%$ de probabilidade.

3 D.M.S. (Diferença Mínima Significativa) para o teste de Tukey, a $5 \%$ de probabilidade.

${ }^{4}$ V4 (emissão da terceira folha trifoliada) e R5 (aparecimento dos botões florais). 
ÁVILA, M.R. et al. Cultivo de feijoeiro no outono/inverno...

Alguns resultados obtidos neste trabalho não estão de acordo com os alcançados por Bevilaqua et al. (2002) com aplicação foliar de Ca e B via pulverização foliar o que promoveu aumento no número de vagens por planta, número de sementes por vagem bem como a massa de sementes por planta, quando aplicados na fase de floração em duas cultivares de soja. Bevilaqua et al. (2002) justificou a causa deste aumento devido ao fato da adubação foliar poder aumentar ou manter a concentração de nutrientes nas folhas, no período de enchimento de grãos, porque nessa fase, a absorção de nutrientes pelas raízes é praticamente nula e que esta prática aumenta o conteúdo de nutrientes na planta e o metabolismo formador de estruturas reprodutivas promovendo assim aumento na produtividade.

O aumento no número de vagens por planta, sementes por vagem, massa de mil sementes e produtividade quando se realizou pulverizações de bioestimulante e adubação com $\mathrm{Ca}+\mathrm{B}$ nas plantas em diferentes estádios fenológicos utilizando irrigação em comparação com os não irrigados, deve-se provavelmente ao déficit hídrico ocorrido em algumas fases do ciclo da cultura. Como observado na Figura 1A, o estresse por restrição hídrica, influenciou no desempenho agronômico da cultura, sobretudo porque afetou o final da fase vegetativa e início da reprodutiva (pré-floração) e também do início da frutificação ao início da maturação, sendo que houve uma redução de produtividade da ordem de $32 \%$, uma vez que a produtividade média dos tratamentos irrigados foi de $775,8 \mathrm{~kg} \mathrm{ha}^{-1}$ versos $527,6 \mathrm{~kg} \mathrm{ha}^{-1}$ dos tratamentos não irrigados (Tabela 4 ) resultado próximo a produtividade da terceira safra Paranaense de feijão no ano agrícola de 2006/07 (CONAB, 2009). A redução de produtividade pode ter sido causada pelo primeiro período de deficiência hídrica. Se esse período se estendesse um pouco mais, atingindo maior parte do período reprodutivo, a queda de produção poderia ser ainda maior. De acordo com Fancelli \& Dourado Neto (1999), o início da fase reprodutiva é a mais crítica quanto à carência de água, havendo brusca redução na emissão de novas folhas e perdas de produção da ordem de 15 a $30 \%$. Alleoni et al. (2000) verificaram que o estresse hídrico causado às plantas de feijoeiro em qualquer período de seu ciclo pode ser prejudicial à ação de bioestimulante.

Embora haja controvérsia sobre o efeito de deficiência hídrica no pré-florescimento, os resultados são unânimes em apontar o florescimento, a formação de vagens e o enchimento de grãos, como as fases mais críticas (Hostalácio \& Válio, 1984; Didonet \& Silva, 2004). Reduções no rendimento ocasionadas por déficit hídrico na fase reprodutiva do ciclo do feijoeiro é resultado do abortamento de flores ou vagens e, da redução do número de sementes por vagem (Andrade et al., 2008), o que também pode ser agravado por ocorrência de altas temperaturas (Tsumanuma \& Lunz, 2008), todavia o mesmo não foi verificado neste experimento (Figura 1C) uma vez que a temperatura ótima para o cultivo do feijoeiro é $21^{\circ} \mathrm{C}$ e a temperatura média durante o ciclo da cultura esteve bastante próxima deste valor.

Os resultados estão de acordo com autores que sinalizam a grande influência da interação entre genótipo e ambientes de produção, no desempenho fenotípico do feijoeiro (Oliveira et al., 2006; Buratto et al., 2007). Desta forma, ressalta-se a importância do cultivo de feijoeiro irrigado em regiões onde há risco potencial da planta passar por períodos de estresse hídrico, há solos com baixa capacidade de retenção de água e principalmente no período de semeadura de outono/inverno.

\section{CONCLUSÕES}

A irrigação devido à frequência de déficits hídricos que ocorreram na região Noroeste do Paraná, se confirma como uma ferramenta para promover o aumento de produtividade da cultura do feijoeiro.

A aplicação de bioestimulante e $\mathrm{Ca}+\mathrm{B}$, associados ou não quando pulverizados em diferentes estádios fenológicos da cultura do feijoeiro não apresentou melhoria no desempenho da cultura.

\section{CONFLITOS DE INTERESSE}

Os autores informam que o conflito de interesses deste trabalho é apenas científico e que buscamos gerar conhecimentos que possam melhorar a utilização de tecnologias agrícolas.

\section{REFERÊNCIAS}

1. ALLEONI, B.; BOSQUEIRO, M.; ROSSI, M. Efeito dos reguladores vegetais de stimulate no desenvolvimento e produtividade do feijoeiro (Phaseolus vulgaris). Publicatio UEPG, v. 6, n. 1, p. 23-35, 2000.

2. ANDRADE, M. J. B.; CARVALHO, A. J.; VIEIRA, N. M. B. Exigências edafoclimáticas. In: VIEIRA, C.; PAULA JR., T. J.; BORÉM, A. (Ed.). 2. ed. Feijão. Viçosa: UFV, 2008. p. 67-86.

3. ÁVILA, M. R. et al. Bioregulator application, agronomic efficiency, and quality of soybean seeds. Scientia Agricola, v. 65, n. 6, p. 604-612, 2008

4. BANZATTO, D. A.; KRONKA, S. N. Experimentação Agrícola. 4. ed. Jaboticabal: FUNEP, 2006. 237 p.

5. BEVILAQUA, G. A. P.; SILVA FILHO, P. M.; POSSENTI, J. C. Aplicação foliar de cálcio e boro e componentes de rendimento e qualidade de sementes de soja. Ciência Rural, v. 32, n. 1, p. 31-34, 2002.

6. BRASIL. Ministério da Agricultura e Reforma Agrária. Regras para análise de sementes. Brasília: SNDA/DNDV/CLAV, 1992. $365 \mathrm{p}$

7. BURATTO, J. S. et al. Adaptabilidade e estabilidade produtiva em genótipos precoces de feijão no estado do Paraná. Semina: Ciências Agrárias, v. 28, n. 3, p. 373-380, 2007. 
ÁVILA, M.R. et al. Cultivo de feijoeiro no outono/inverno...

8. CASTRO, P. R. C.; VIEIRA, E. L. Aplicações de reguladores vegetais na agricultura tropical. Guaíba:Agropecuária, 2001. $132 \mathrm{p}$

9. COMPANHIA NACIONAL DE ABASTECIMENTO (CONAB). Safra 2006/07 - Séries históricas. Disponível em: <http:// www.conab.gov.br/conabweb/download/safra/FeijaoTotalSerieHist.xls>. Acesso em: 03 jul. 2009.

10. DIDONET, A. D.; SILVA, S. C. Elementos climáticos e produtividade do feijoeiro. Informe Agropecuário, v. 25, n. 223, p. 13-19, 2004.

11. DOORENBOS, J.; KASSAM, A. H. Efeito da irrigação no rendimento das culturas. Campina Grande: Universidade Federal de Paraíba, 1994. 306 p. (FAO, Estudos de irriguação e drenagem, 33)

12. EMPRESA BRASILEIRA DE PESQUISA AGROPECUÁRIA (EMBRAPA). Sistema brasileiro de classificação dos solos. 1. ed. Brasília: EMBRAPA, 1999. 412 p.

13. FANCELLI, A. L.; DOURADO NETO, D. Estresse de água e temperatura na cultura do feijão. In: FANCELLI, A. L.; DOURADO NETO, D. (Ed.). Feijão irrigado: estratégias básicas de manejo. Piracicaba: Publique, 1999. p. 155-169.

14. GOMES, E. P., TESTEZLAF, R. Manejo de irrigação na tomaticultura de mesa. Disponível em: <http:// ww.feagri.unicamp.br/tomates/index.htm> Acesso em: 23 dez. 2008.

15. HOFFMANN, R. Elasticidade das despesas com alimentos em regiões metropolitanas do Brasil em 1995-96. Informações Econômicas, v. 30, n. 2, p. 17-24, 2000.

16. HOSTALÁCIO, S.; VALIO, I. F. M. Desenvolvimento de plantas de feijão cv. Goiano precoce, em diferentes regimes de irrigação. Pesquisa Agropecuária Brasileira, v. 19, n. 2, p. 211-218, 1984.

17. JADOSKI, S. O. et al. Manejo da irrigação para maximização do rendimento de grãos do feijoeiro. Revista Irriga, v. 8 , n. 1, p. 1-9, 2003

18. MALAVOLTA, E.; VITTI, G. C.; OLIVEIRA, S. A. Avaliação do estado nutricional das plantas: princípios e aplicações. 2. ed. Piracicaba: POTAFÓS, 1997. 319 p.

19. MILLÉO, M. V. R. et al. Avaliação da eficiência agronômica do produto Stimulate aplicado no tratamento de sementes e no sulco de plantio sobre a cultura do milho (Zea mays L.). Arquivos Instituto Biológico, v. 67, n. 1, p. 1-145, 2000

20. OlIVEIRA, G. V. et al. Adaptabilidade e estabilidade de linhagens de feijão comum em Minas Gerais. Pesquisa Agropecuária Brasileira, v. 41, n. 2, p. 257-265, 2006.

21. REZENDE, R. et al. Uniformidade de aplicação de água, variáveis de produção e índice de área foliar da cultivar de feijão lapar 57. Acta Scientiarum Agronomy, v. 24, n. 5, p. 1561-1568, 2002.

22. REZENDE, R. et al. Função de produção da cultura do milho e do feijão para diferentes lâminas e uniformidade de aplicação de água. Acta Scientiarum Agronomy, v. 26, n. 4, p. 503-511, 2004.

23. ROLIM, G. S.; SENTELHAS, P. C. Balanço hídrico normal por Thornthwaite \& Mather (1955) - BHNORM V 5.0. Piracicaba: Departamento de Física e Meteorologia, ESALQ-USP, 1999.

24. TAIZ, L.; ZEIGER, E. Plant plysiology. 4. ed. Sunderland: Sinauer Associates, 2006. 705 p.

25. THORNTHWAITE, C. W.; MATHER, J. R. The water balance. New Jersey: Drexel Institute of Technology, 1955. $104 \mathrm{p}$.

26. TSUMANUMA, G.M.; LUNZ, A.M.P. Feijoeiro. In: CASTRO, P. R. C.; KLUGE, R. A.; SESTARI, I. Manual de fisiologia vegetal: fisiologia de cultivos. Piracicaba: Ceres, 2008. p. 77-91.

27. VIEIRA, E. L.; CASTRO, P. R. C. Ação de bioestimulante na cultura da soja (Glycine max (L.) Merrill). Cosmópolis: Stoller do Brasil, 2004. 73 p.

28. VIEIRA, E. L.; MONTEIRO, C. A. Hormônios vegetais. In: CASTRO, P.R.C.; SENA, J. O. A.; KLUGE, R. A. (Ed.) Introdução à fisiologia do desenvolvimento vegetal. Maringá: EDUEM, 2002. p. 79-104.

29. VIEIRA, C. Adubação mineral e calagem. In: VIEIRA, C.; PAULA JR., T. J.; BORÉM, A. (Ed.). 2. ed. Feijão. Viçosa: UFV, 2008. p. 115142.

Recebido em 26/02/2009

Aceito em 02/12/2009 